\title{
ANÁLISIS DEL CASO COUSO A LA LUZ DEL ESTATUTO DE ROMA*
}

\author{
Héctor OLÁSOLO ALONSO ** \\ LETRADO DE LA CORTE PENAL INTERNACIONAL \\ PROFESOR DE DERECHO PENAL \\ UNIVERSIDAD DE UTRECHT
}

\section{s u m a r i o}

I. Introducción. II. Observaciones preliminares sobre la tipificación de los ataques dirigidos contra personas y bienes civiles y de los ataques desproporcionados en el Estatuto de Roma. III. Las jurisdicciones nacionales como principal instrumento en la persecución penal de los crímenes de guerra. IV. Análisis del caso Couso. IV.r. Jurisdicción, Admisibilidad y Marco Procesal Aplicable. IV.2. El Umbral de Gravedad como Condición Objetiva de Procedibilidad. IV.3 Elementos contextuales. IV.4 Estructura típica de los crímenes de guerra de lanzar ataques contra personas o bienes civiles o de lanzar ataques desproporcionados en el Estatuto de Roma. IV.5 Análisis de los hechos del caso Couso a la luz de la tipificación de los ataques contra personas y bienes civiles y de los ataques desproporcionados en el ER. V. Conclusión.

\section{Introducción}

El 8 de abril del 2003, las tropas norteamericanas realizaban una «operación de limpieza» dirigida a obtener definitivamente el control sobre ciertas áreas de Bagdad. ${ }^{\mathrm{I}}$ En el

\footnotetext{
"Este artículo es el resultado de una estancia como profesor visitante en la Facultad de Derecho de la Universidad de la Rioja

* El autor tiene una maestría por la Universidad de Columbia, es doctor en derecho por la Universidad de Salamanca, y actualmente se desempeña como letrado de Sala de la Corte Penal Internacional y como profesor asociado del departamento de derecho penal y procesal penal de la Universidad de Utrecht. El ha sido miembro de la delegación española en la Comisión Preparatoria para el establecimiento de la Corte Penal Internacional (I999-2002) y letrado de la Fiscalía del Tribunal Penal Internacional para la Antigua Yugoslavia. Las opiniones expresadas en este artículo son aquellas personales del autor y no se corresponden necesariamente con aquellas de la Corte Penal Internacional, del Tribunal Penal Internacional para la Antigua Yugoslavia o de las Naciones Unidas en general, o del gobierno español
} 
marco de esta operación, hacia las 7.50 h. de la mañana del día 8 de abril del 2003, bajo el mando de la Tercera División de Infantería del Ejército de los Estados Unidos, un misil lanzado desde un avión de combate estadounidense alcanza las sedes de la cadena Al-Yazira y de la televisión Abu Dhabi en Bagdad ${ }^{2}$, causando la muerte al periodista jordano Tarek Ayub e hiriendo a su cámara.

Poco después de las once de la mañana, la tripulación de un carro de combate estadounidense Abrams Mi, perteneciente a la compañía A del Regimiento 64 de la Segunda Brigada de la Tercera División de Infantería, giró su torreta para apuntar al Hotel Palestina -lugar donde una buena parte de la prensa internacional se encontraba ubicada de acuerdo con las indicaciones dadas por el Pentágono- a raíz de la identificación de lo que en principio se dijo era un francotirador enemigo y, posteriormente, parece ser que se trataba de un observador con prismáticos.

Tras una espera de varios minutos, y con la pertinente autorización de sus superiores jerárquicos (ya fuese el capitán Wolford o el teniente coronel Philip de Camps), el sargento Gibson disparó desde el carro de combate Abrams Mi un proyectil que impactó contra el piso I5 del Hotel Palestina. José Couso Permuy, cámara y reportero de Tele 5, fue alcanzado por el impacto mientras se encontraba filmando desde la habitación I403 del Hotel Palestina, falleciendo pocas horas después a causa de las heridas recibidas. En el ataque falleció también Taras Protsyuk, periodista de la agencia Reuters, quién se encontraba en la habitación I503, y resultaron heridos de gravedad Samia Najul, periodista libanesa, Paul Pasquale, coordinador de satélite de nacionalidad británica y el fotógrafo iraquí Faleh Kheiber -hubo además varios heridos de menor consideración.

Según fuentes del Pentágono, la Tercera División de Infantería tenía todos los motivos para creer que existía un francotirador en el hotel Palestina, y además desconocía que en el hotel Palestina se encontraban alojados los corresponsales de la prensa internacional'. Por su parte, el Secretario de Estado, Colin Powell, en una carta dirigida a la ministra de asuntos exteriores española, Ana Palacio, el 2I de abril de 2003 afirma que el uso de la fuerza estuvo justificado y el nivel de fuerza fue proporcional a la amenaza contra las fuerzas norteamericanas. En el mismo sentido, el Departamento de Defensa norteamericano en su informe en respuesta a una petición del Comité para la Protección de

${ }^{\mathrm{I}}$ La descripción de los hechos del caso está basada en los hechos descritos en (i) la sentencia del Tribunal Supremo de in de diciembre de 2006 por la que se reconoce la jurisdicción del a justicia española para investigar los hechos que ocasionaron la muerte de José Couso, y que priva de toda eficacia la anulación de la orden de búsqueda y captura dictada por el Juzgado Central de Instrucción Núm. I contra los tres principales imputados y el archivo de la querella decretados en marzo de 2006 por la Sala de lo Penal de la Audiencia Nacional; (ii) el auto de i9 de octubre de 2005 del Juzgado Central de Instrucción Núm. I por el que dicta orden de búsqueda y captura contra los tres principales imputados; (iii) la querella interpuesta ante el Juzgado Central de Instrucción Núm. I de la Audiencia Nacional el 27 de mayo de 2003 (disponible en

$<$ http://www.josecouso.info/IMG/pdf/querella.pdf>); y (iv) el informe del Comité para la Protección de Periodistas (CPP), disponible en:

< www.cpj.org/Briefings/2003/palestine_hotel/palestine_hotel.html>.

${ }^{2}$ La sede de Al Yazira en Bagdad se encontraba ubicada en un edificio residencial, cuyas coordenadas habían sido proporcionadas por la propia cadena de televisión al Pentágono dos meses antes. Además, amplias banderas con el símbolo «TV» colgaban de dicho edificio.

${ }^{3}$ Las declaraciones del capitán Wolford, superior inmediato que autorizó al sargento Shawn Gibson, que se encontraba al mando del carro de combate Abrams Mr, a efectuar el disparo contra el hotel Palestina, resultan algo confusas ya que por un lado señala que el carro de combate que disparó al hotel Palestina estaba «devolviendo» el fuego, mientras que por otro lado afirma rotundamente que el carro disparó contra un vigía con prismáticos. Por su parte, el sargento Shawn Gibson afirma que la compañía A del Regimiento 64 de segunda Brigada de la Tercera División de Infantería, que se encontraba en el puente Al-Jumhuriya cuando las tropas norteamericanas entraron en el centro de Bagdad, buscaba en realidad a un observador de la artillería iraquí, al que intentaba neutralizar. 
los Periodistas («CPP») -organización norteamericana que investiga casos de violencia contra periodistas en todo el mundo- en virtud de la Ley de Libertad de Información sostiene que el ataque contra el hotel Palestina se efectuó en defensa propia porque que la tripulación del carro de combate tenía razones para creer que en dicho hotel se encontraban fuerzas enemigas disparando sobre las tropas estadounidenses. Además, según el Pentágono, la responsabilidad recae en todo caso sobre el enemigo porque «eligió combatir en una ciudad, exponiendo innecesariamente a la población civil, incluidos los periodistas». Por todo ello, el Pentágono concluye que en el ataque al hotel Palestina que causó la muerte al periodista español José Couso Permuy no se puede apreciar que existiera imprudencia alguna.

Por su parte, el CPP, en un comunicado emitido el 25 de junio de 2003 basado en algunas comunicaciones de radio interceptadas, afirma que los soldados que abrieron fuego sólo tenían la certeza de estar siendo observados desde un edificio suficientemente alto, y recuerda que ninguno de los periodistas alojados en el hotel Palestina indicaron que saliera fuego hostil desde el hotel. Es más, muchos aseguraron que durante los quince o veinte minutos previos ni siquiera hubo fuego en la zona, y daba la impresión de que los combates habían terminado ${ }^{4}$.

El CPP denuncia que las conclusiones del Pentágono no explicaban las razones por las que las tropas estadounidenses no sabían que el hotel Palestina estaba repleto de periodistas internacionales, cuando las agencias de noticias habían informado previamente a los mandos militares norteamericanos de dónde se alojaban sus corresponsales. Según el CPP, parece ser que dichos mandos militares no informaron al respecto a sus subordinados 5 . En consecuencia, el CPP concluye que el ataque contra los periodistas alojados en el hotel Palestina, si bien no fue premeditado, se pudo evitar.

Finalmente, en la querella presentada por los familiares de José Couso Permuy ${ }^{6}$, se afirma el carácter civil del hotel Palestina, así como el hecho de que las fuerzas y mandos angloamericanos conocían que en dicho hotel se alojaba la prensa internacional. Según se afirma en la querella, tanto el ataque contra el hotel Palestina como el ataque contra las sedes de Al-Yazira y Abu Dhabi, fueron inmediatamente reconocidos por el mando central aliado en Qatar. Ahora bien, la justificación ofrecida en relación con el hotel Palestina, es decir la existencia de un francotirador en el tejado, no es confirmada por el testimonio de ninguno de los numerosos periodistas presentes en el lugar de los hechos.

Por esta razón, la querella presentada por la acusación particular ante el Juez Central de Instrucción Núm. I de la Audiencia Nacional el 27 de mayo de 2003, califica los hechos relatados en la misma, desde la perspectiva del ER, de la siguiente manera:

«Los hechos relatados constituyen, desde la perspectiva del derecho internacional, 'crimen de guerra'». Según el Estatuto de Roma, que dio lugar a la creación del la Corte Penal Internacional, firmado por España el día I8 de julio de i998 y ratificado el 24 de octubre de 2000 , se entienden por crímenes de guerra:

- Artículo 8.2 a) Infracciones graves de los Convenios de Ginebra de I2 de agosto de I949, a saber, cualquiera de los actos contra personas o bienes protegidos por las disposiciones del Convenio de Ginebra pertinente: ii) Dirigir intencionalmente ataques contra bienes civiles, es decir, bienes que no son objetivos militares.

\footnotetext{
${ }^{4}$ El Informe puede verse en <http://www.cpj.org/Briefings/2003/palestine_hotel/palestine_hotel.html>.

${ }^{5}$ Surge el interrogante de: ¿por qué no se informó a las unidades militares antes del ataque de la presencia de un emplazamiento civil de importancia en el campo de batalla?

${ }^{6}$ Ver http://www.josecouso.info/IMG/pdf/querella.pdf.
} 
La Convención de Ginebra establece en su Protocolo Adicional I de 8 de junio de I977:

- Art. 5I.I: «La población civil y los civiles deberán gozar de protección civil contra los peligros inherentes a las operaciones militares».

- Art. 5I.4, 5: Para hacer efectiva la protección a la población se prohíben los ataques indiscriminados. Se consideran ataques indiscriminados: Art. 5I.4 a) «los que no están dirigidos contra objetivo militar concreto». Art. 5I.5 b) «los ataques, cuando sea prever que causarán incidentalmente muertos y heridos entre población civil, o daños a bienes de carácter civil, o ambas cosas».

- Art. 79: «Los periodistas que realicen misiones profesionales peligrosas en la zona de conflicto armado serán consideradas personas civiles. Deberán ser protegidas como tales de conformidad con el presente Convenio y el presente Protocolo, a condición de que abstengan de todo acto que afecte a su estatuto de persona civil»?

\section{Observaciones preliminares sobre la tipificación de los ataques dirigidos contra personas y bienes civiles y de los ataques desproporcionados en el Estatuto de Roma}

A pesar de las dificultades a que se enfrentan quienes participan en un conflicto armado (especialmente durante situaciones de combate), el derecho internacional humanitario, también llamado derecho internacional de los conflictos armados, exige a los mismos el respeto de ciertas reglas básicas que pretenden limitar los sufrimientos y destrucción causados por el conflicto -en particular los ocasionados a aquéllas personas que no han participado o que han dejado de participar en el mismo ${ }^{8}$. Por ello, el derecho internacional humanitario obliga en la misma medida a todas las partes contendientes con independencia de quién recurrió primero al uso de la fuerza armada y de las razones para ello?.

Esto no puede, sin embargo, equipararse con la prohibición del empleo letal o devastador de la fuerza. Por el contrario, muerte y destrucción, incluso cuando afecta a civiles, son efectos inevitables de los conflictos armados, y no se encuentran prohibidos como tales por el derecho internacional humanitario. Por tanto, de su existencia no se puede presumir sin más que se haya cometido un crimen de guerra. Sólo cuando muerte y destrucción son el resultado de infracciones graves del derecho internacional humanitario se puede hablar de responsabilidad penal individual.

En consecuencia, prácticas como la de catalogar como crímenes contra la humanidad -o incluso como delitos ordinarios- ataques perfectamente lícitos desde la perspectiva del derecho internacional humanitario por el mero hecho de que causan bajas civiles o daños a bienes de carácter civil ${ }^{10}$ no sólo es contraria a la normativa que regula los

\footnotetext{
${ }^{7}$ Idem.

${ }^{8}$ REMIRO BRotónS, A., «Los crímenes de Derecho internacional y su persecución judicial», en $E l$ Derecho Penal Internacional, Cuadernos de Derecho Judicial, Escuela Judicial Consejo General del Poder Judicial, 200I, pp. I42 y ss.

${ }^{9}$ Quintano Ripollés, A., Tratado de Derecho Penal Internacional e Internacional Penal, Madrid: Consejo Superior de Investigaciones Científicas, Instituto «Francisco de Vitoria», Tomo I, pp. 573 y 574 .

Io Ejemplo paradigmático de esta práctica es el análisis de los ataques a los pueblos de Vitez y Donja Veceriska, ambos situados en el valle del río Lasva en Bosnia Central, por las fuerzas bosniocroatas (HVO) entre el I6 y el I8 de abril de I993 en los párrafos 643 a 649 de la Sentencia de primera instancia del Tribunal Penal Internacional para la antigua Yugoslavia («TPI») en el caso Prosecutor v. Dario Kordic and Mario Cerkez, caso núm. IT-95-I4/2-T, de 26 de febrero de 200 I.
} 
conflictos armados (y en particular las situaciones de combate), sino que introduce estándares de imposible cumplimiento que eliminan todo incentivo para que las partes contendientes ajusten su comportamiento a los mismos y reduce drásticamente la eficacia preventivo general de sus normas penales.

No todas las infracciones del derecho internacional humanitario dan lugar a responsabilidad penal individual. En principio, sólo las infracciones más graves del derecho internacional humanitario, denominadas crímenes de guerra, dan lugar a la responsabilidad penal de sus autores y de aquellos otros que contribuyen a su comisión ${ }^{\text {II }}$. Así, los Convenios de Ginebra de I949, estipulan en el párrafo primero de los arts. 49 CG I, 50 CG II, I29 CG III y I46 CG IV que «las Altas Partes contratantes se comprometen a tomar todas la medidas legislativas necesarias para fijar las adecuadas sanciones penales que cometan, o den orden de cometer, cualesquiera de las infracciones graves al presente Convenio, definidas en el artículo siguiente». Además, en el párrafo tercero de estas mismas disposiciones se añade que «cada Parte contratante tomará las medidas necesarias para que cesen los actos contrarios a las disposiciones del presente Convenio, aparte de las infracciones graves definidas en el artículo siguiente».

El sistema es completado por el art. 85(I) del Protocolo I Adicional a los Convenios de Ginebra («PA I») que señala que «las disposiciones de los Convenios relativas a las represión de las infracciones y de las infracciones graves, completadas por la presente Sección, son aplicables a la represión de las infracciones y de las infracciones graves del presente Protocolo»; mientras que en el párrafo quinto del mismo artículo se añade que «sin perjuicio de la aplicación de los Convenios y del presente Protocolo, las infracciones graves de dichos instrumentos se considerarán como crímenes de guerra».

En principio, el resto de violaciones de la normativa de derecho internacional humanitario sólo da lugar, según los casos, a responsabilidad administrativa o disciplinaria y, en ciertos supuestos, a una simple obligación de los Estados a adoptar las medidas legislativas necesarias para poner fin a las mismas ${ }^{\mathrm{I}}$. Sin embargo, debido a la tradicional

Véase a este respecto el distinto tratamiento que del ataque a Donja Veceriska realiza la Sentencia de primera instancia en el caso Prosecutor v. Tihomir Blaskic, caso Núm. IT-95-I4-T, de 3 de marzo de 2000 (pàrrafos 533-544). En cualquier caso, esta práctica del TPIY parece haber sido definitivamente superada como así lo indica la Sentencia de primera instancia en el caso Prosecutor v. Stanislav Galic, caso núm. IT-98-29-T, de 5 de diciembre de 2003, párrafo I44.

II No todas las infracciones del derecho internacional humanitario dan lugar a responsabilidad penal individual. De hecho, mientras las primeras limitaciones conocidas a la manera de conducirse en las hostilidades datan del guerrero chino Sun Tzu en el siglo VI a.c. -habiendo sido los griegos los primeros en atribuir a estas prohibiciones el valor de ley- hay que esperar al Código hindú Manu hacia el año 200 a. c. par encontrar la primera elaboración comprehensiva de la noción de crimen de guerrra, que eventualmente sería integrada en el derecho romano. Ver RATNER, R., «Crímenes de Guerra, Clases de», en GuTMAn y RiefF (Coord.), Crímenes de Guerra. Lo que Debemos Saber, Debates, 2003, p. I45; y AMATI, E., «La Repressione dei Crimini di Guerra tra Diritto Internazionale e Diritto Interno», en Illuminati, STORTONI y Vigilio (Coord.), Crimini internacionali tra Diritto e Giustizia. Dai Tribunali Internazionali alle Comisión Veritá e Riconciliazione, Torino: Giappichelli, 2000, p. IO2.

${ }^{\mathrm{I} 2}$ Los arts. 49 CG I, 50 CG II, I29 CG III y I46 CG IV disponen que «cada Parte Contratante tomará las oportunas medidas para que cesen, aparte de las infracciones graves definidas en el artículo siguiente, los actos contrarios a las disposiciones del presente Convenio». Por su parte el art. 85(I) PA I establece que «las disposiciones de los Convenios relativas a la represión de las infracciones y de las infracciones graves, completadas por la presente Sección, son aplicables a la represión de las infracciones y de las infracciones graves del presente Protocolo». Además, el art. 86(I) PA I añade que «las Altas Partes contratantes y las Partes en conflicto deberán reprimir las infracciones graves y adoptar las medidas necesarias para hacer que cesen todas las demás infracciones de los Convenios o del presente Protocolo que resulten del incumplimiento de un deber de actuar», mientras que el art. 87(3) PA I dispone que «las Altas Partes contratantes y las Partes en conflicto obligarán a todo jefe que tenga conocimiento de que sus subordinados $u$ otras personas 
reticencia de los Estados a tipificar mediante tratados internacionales aquellos comportamientos que más gravemente menoscaban los valores superiores sobre los que se asienta la comunidad internacional, la costumbre ha tenido tradicionalmente un papel particularmente relevante como fuente de derecho penal internacional ${ }^{13}$. De ahí, que, a diferencia de lo que ocurre en los ordenamientos jurídicos nacionales donde el derecho consuetudinario no es fuente de derecho penal, sea necesario prestar atención al derecho consuetudinario para determinar el conjunto de infracciones del derecho internacional humanitario que dan lugar a responsabilidad penal individual ${ }^{14}$.

En este sentido, la Sala de Apelaciones común a los tribunales ad hoc ha afirmado en su decisión sobre jurisdicción en el caso Tadic la existencia de un núcleo duro de normas consuetudinarias de derecho internacional humanitario cuya infracción grave da

bajo su autoridad van a cometer o han cometido una infracción de los Convenios o del presente Protocolo a que tome las medidas necesarias para impedir tales violaciones de los Convenios o del presente Protocolo y, en caso necesario, promueva una acción disciplinaria o penal contra los autores de las violaciones».

${ }^{13}$ Conforme al artículo 38 del Estatuto de la Corte Internacional de Justicia, las fuentes del derecho internacional son las siguientes: (i) las convenciones internacionales, ya sean generales o particulares, que establecen las reglas expresamente reconocidas por los Estados que las suscriben; (ii) la costumbre internacional como prueba de una práctica generalmente aceptada como derecho; (iii) los principios generales de derecho reconocidos por las naciones civilizadas; y (iv) las decisiones judiciales y las doctrinas de los publicistas de mayor competencia de las distintas naciones, como medio auxiliar para la determinación de las reglas de derecho.

${ }^{\text {I4 }}$ En este sentido, la Sala de Apelaciones común a los tribunales ad hoc ha señaló en su decisión sobre jurisdicción de 2 de octubre de 1995 en el caso Prosecutor v. Dusko Tadic, caso núm. IT-94-IAR72, (párrafo I43), que tanto la costumbre internacional como el derecho convencional son fuentes de derecho penal internacional relevantes a los efectos de analizar el cumplimiento de las exigencias derivadas del principio nullum crimen sine lege. Si bien la aplicación del derecho convencional se encuentra sometida a las siguientes dos condiciones: (i) la adhesión de todas las partes en conflicto al tratado internacional de que se trate en el momento en que se produzcan los hechos presuntamente constitutivos de delito; y (ii) la compatibilidad entre el contenido de las normas convencionales de que se trate y las normas internacionales de ius cogens, entre las que se encuentran la mayoría de los usos y costumbres de la guerra (Decisión sobre jurisdicción en el caso Tadic, párrafo I43). En la misma decisión (párrafo I43) la Sala de Apelaciones añadió que los redactores del estatuto del TPIY habían hecho particular énfasis en la aplicación del derecho consuetudinario para evitar así la violación del principio nullum crimen sine lege en aquellos supuestos en los que alguna de las partes en conflicto no fuese parte del tratado internacional relevante.

Más recientemente la Sala de Apelaciones, sobre la base del informe del Secretario General de las Naciones Unidas, ha señalado que, en principio, sólo puede aplicar aquellas normas del derecho internacional humanitario sobre las que no hay duda de su carácter consuetudinario, de manera que el TPIY sólo puede conocer de hechos que en el momento de producirse fuesen constitutivos de delito conforme a la costumbre internacional. Este cambio se dejó entrever por primera vez en la decisión interlocutoria de 22 de noviembre de 2002 en el caso Prosecutor v. Pavle Strugar, caso núm. IT-oI-42-AR72 (párrafos 9, Io y I3) en relación con los ataques dirigidos contra personas o bienes civiles. Posteriormente se ha consolidado con la decisión sobre jurisdicción respecto de la doctrina del propósito criminal común de I2 de mayo de 2004 en el caso Prosecutor v. Milan Milutinovic, Nikola Sainovic and Dragoljub Ojdanic, caso núm. IT-99-37-AR72 (párrafo 9), la decisión sobre jurisdicción en relación con la responsabilidad de los superiores jerárquicos de 16 de julio de 2003 en el caso Prosecutor v. Enver Hadzihasanovic, Mehmed Alagic and Amir Kubura, caso núm. IT-oI-47AR72 (párrafo 32), la Sentencia de Apelación de 22 de marzo de 2006 en el caso Prosecutor $v$ Milomir Stakic, caso núm. IT-92-24-A (párrafo 62), y la Sentencia de Apelación de 30 de noviembre de 2006 en el caso Prosecutor v. Stanislav Galic, case núm IT-98-29-A.

La tradicional importancia del derecho consuetudinario para determinar el conjunto de infracciones del derecho internacional humanitario que dan lugar a responsabilidad penal individual se ha reflejado también en los criterios aplicados en la selección de los comportamientos típicos incluidos en el ER. Ver a este respecto, Von Hebel, H. y ROBInSON, D., "Crimes within the Jurisdiction of the Court», en LEE, R.S. (Coord.), The International Criminal Court. The Making of the Rome Statute, Kluwer Law International, I999, pp. I03-I04. 
lugar a responsabilidad penal con independencia de que se actúe en el contexto de un conflicto armado de carácter internacional o de carácter interno ${ }^{15}$. Entre estas normas se incluyen la prohibición de realizar actos de violencia contra todos aquellos que no toman parte activa o que han dejado de tomar parte activa en las hostilidades, la protección de los bienes de carácter civil (así como de los bienes históricos, culturales o dedicados a ciertas finalidades sociales), la prohibición del lanzamiento de ataques indiscriminados o de ataques que se prevé causarán daños civiles colaterales excesivos en relación con la ventaja militar esperada de los mismos y la prohibición de ciertos métodos y medios de combate ${ }^{\mathrm{i} 6}$.

Como resultado de esta evolución, el Estatuto de Roma («ER»), al menos en relación con los conflictos armados de carácter internacional, tipifica por separado los ataques que más gravemente infringen el núcleo central de la normativa que desarrolla el principio de distinción en la conducción de las hostilidades, es decir: (i) los ataques dirigidos contra la población civil en cuanto tal o contra personas civiles que no participan directamente en las hostilidades; (ii) los ataques dirigidos contra bienes civiles, es decir, aquellos que no constituyen objetivos militares $^{17}$; y (iii) los ataques desproporcionados contra objetivos militares, es decir, aquellos que se prevé causarán daños civiles colaterales manifiestamente excesivos en relación con la ventaja militar concreta y directa de conjunto que se prevea obtener de los mismos ${ }^{\text {18 }}$.

Con ello se reconoce la distinta naturaleza entre los ataques ilícitos lanzados contra personas o bienes que no tienen la condición de objetivo militar y aquellos otros ataques que, si bien en principio podrían ser considerados lícitos en cuanto que son

\footnotetext{
${ }^{15}$ Decisión sobre jurisdicción en el caso Tadic, supra nota I6, párrafos III, I26, I27, I34 y I43.

${ }^{16}$ Idem. Más recientemente, la Sala de Apelaciones ha subrayado en su Decisión interlocutoria en el caso Strugar, supra nota I6, párrafos 9, I0 y I3, la naturaleza consuetudinaria de los delitos relativos a los ataques dirigidos contra personas o bienes civiles.
}

${ }^{17}$ Arts. 8(2)(b)(i) y (ii) y (2)(e)(i) ER.

${ }^{18}$ Art. 8(2)(b)(iv) ER. Los redactores del ER llevaron a cabo un proceso de selección de las infracciones graves del derecho internacional humanitario que fueron finalmente tipificadas en el ER a los efectos de asegurar que la jurisdicción material de la Corte se limite a «los crímenes más graves de trascendencia para la comunidad internacional en su conjunto» ${ }^{\mathrm{I}}$. Tres fueron los criterios utilizados por los redactores del ER para determinar a priori qué infracciones del derecho internacional humanitario merecían ser incluidas en el ER y cuáles otras debían ser excluidas. Los criterios elegidos fueron los siguientes: (i) que con independencia de su posible origen convencional, la norma afectada hubiese alcanzado la condición de costumbre internacional y por tanto vinculase a todos los Estados miembros de la comunidad internacional; (ii) que al margen de las consecuencias previstas en los instrumentos internacionales donde dicha norma se recogiese, su violación diera lugar a responsabilidad penal de acuerdo con el derecho internacional consuetudinario; y (iii) que dicha violación entrañase a priori la gravedad suficiente. Ver VON HEBEL, H. Y ROBINSON, D., «Crimes within the Jurisdiction of the Court», en LEE, R.S. (Coord.), The International Criminal Court. The Making of the Rome Statute, I999, pp. I03-I04. Ver también OlÁsolo, H., «Apuntes Prácticos sobre el Tratamiento de los Crímenes de Guerra en el Estatuto de Roma sobre la Corte Penal Internacional», Revista Española de Derecho Militar 86, julio-diciembre de 2005, pp. I07 y ss. Como consecuencia, no todas las conductas incluidas en el sistema de infracciones graves de los Convenios de Ginebra y del PA I fueron tipificadas en el ER. Sirva como ejemplo la exclusión de la infracción grave del art. 85(4)(b) PA I relativa a la «demora injustificable en la repatriación de prisioneros de guerra o de personas civiles». Ver a este respecto, CASSESE, A., International Criminal Law, Oxford University Press, 2003, pp. 6o-6r. La importancia de esta exclusión es palpable si tenemos en cuenta lo acontecido por ejemplo al final de la segunda guerra mundial (FISCHER, H., «Protection of Prisoners of War», en FLECK D. (Coord.), The Handbook of Humanitarian Law in Armed Conflicts, pp. 321-368, pp. 324-32). 
lanzados contra objetivos militares, acaban en última instancia siendo ilícitos por infringir gravemente la regla de proporcionalidad ${ }^{19}$.

Es precisamente a la luz de estos tres tipos penales, desde los que hay que analizar si operaciones militares como la que costó la vida a José Couso Permuy el 8 de abril del 2003 dan lugar a la responsabilidad penal de sus autores conforme al ER. Además, al llevar a cabo dicho análisis conviene recordar que el carácter lícito o ilícito del conflicto armado es irrelevante a la hora de analizar si una determinada operación militar se desarrolla de conformidad con el principio de distinción y la regla de proporcionalidad.

\section{Las jurisdicciones nacionales como principal instrumento en la persecución penal de los crímenes de guerra}

La creación de la Corte Penal Internacional («la Corte») no sólo no afecta a la configuración de las jurisdicciones nacionales como el principal instrumento en la investigación y enjuiciamiento de los crímenes de guerra sino que, por el contrario, lo refuerza ${ }^{20}$.

Desde una perspectiva sustantiva, la eficacia de la función preventiva de las normas penales recogidas en el ER -y de la actuación del principio de legalidad penal recogido en los arts. 22 a 24 ER- requiere en una importante medida la adopción en las legislaciones internas de los tipos penales previstos en el ER. Esta es la consecuencia lógica de la estructura de la norma penal conforme a la cuál la amenaza de sanción penal en caso de menoscabo del bien jurídico protegido se dirige a individuos, de manera que, al margen de los esfuerzos educativos sobre el contenido de la norma, la cercanía de la fuente normativa al individuo constituye un factor de indudable relevancia en el conocimiento de su contenido y, por lo tanto, en la eficacia de su función preventiva.

La claridad del mensaje enviado por la norma penal constituye también un factor esencial en su eficacia preventiva y en la realización de las garantías fundamentales derivadas del principio de legalidad penal. Esta claridad se transformaría inevitablemente en confusión, no importa la simplicidad con que las normas contenidas en el ER hayan sido redactadas, si el individuo percibiese que los mensajes enviados por la normativa interna y la internacional no se corresponden. Por esa razón, el ER se construye sobre la afirmación de la obligación de cada Estado de ejercer su jurisdicción penal contra los responsables de crímenes internacionales $^{21}$, lo que presupone la obligación previa de incorporarlos en sus respectivas legislaciones nacionales, particularmente a la luz de las exigencias internas derivadas del principio de legalidad penal y del carácter no auto-ejecutivo de las normas penales internacionales -el cuál se predica incluso de aquellas normas que tiene un mayor

I9 Una posición diferente es sostenida por GARDAM, J.G., «Proportionality and Force in International Law», en American Journal of International Law, Vol. 87, I993, pp. 39I y ss, p. 4Io; y por Murphy, J.F., «Some Legal (And A Few Ethical) Dimensions Of The Collateral Damage Resulting From NATO's Kosovo Campaign», en WALL, A. (Coord.), Legal and Ethical Lessons of NATO's Kosovo Campaign, International Law Studies, Vol. 78, 2002, pp. 244-245 y 248.

${ }^{20}$ OlÁsolo Alonso, H., «Reflexiones sobre el Principio de Complementariedad en el Estatuto de Roma», en Revista Española de Derecho Militar 82, julio-diciembre 2003, pp. 60-6I.

${ }^{21}$ Párrafo sexto del Preámbulo del ER. Ver sobre este punto, OlÁsolo Alonso, H., Corte Penal Internacional: ¿Dónde Investigar? Especial Referencia a la Fiscalía en el Proceso de Activación, Valencia: Tirant lo Blanch/Cruz Roja Española, 2003, pp. 80-82. 
grado de precisión y especificidad como las relativas a las infracciones graves de los Convenios de Ginebra o del PA I ${ }^{22}$.

Pero el ER también pretende reforzar la eficacia de la sanción de los crímenes de guerra a nivel nacional mediante la creación de un órgano jurisdiccional de carácter permanente que complementa a las jurisdicciones nacionales y las incentiva a ejercer su jurisdicción sobre los tipos penales recogidos en el art. 8 del ER. En efecto, el ER, lejos de pretender sustituir a las jurisdicciones nacionales en la sanción de los crímenes de guerra, las complementa desde diversas perspectivas ${ }^{23}$.

En primer lugar, la creación de la Corte no impide que las jurisdicciones nacionales continúen actuando como la única instancia para la sanción de aquellos crímenes de guerra que se encuentran fuera de la jurisdicción material, personal, temporal o territorial de la Corte $^{24}$. Esto ocurrirá cuando nos encontremos con conductas que dan lugar a responsabilidad penal conforme al derecho internacional humanitario pero que no han sido tipificadas por el $\mathrm{ER}^{25}$. Este será también el caso cuando, ausente una remisión del Consejo de Seguridad conforme al art. I3(b) ER, los crímenes de guerra se hayan presuntamente cometido en el marco de una situación de crisis ocurrida en el territorio y entre nacionales de Estados no Parte ${ }^{26}$. Finalmente, este escenario también podrá generarse cuando los Estados Partes hagan uso de la moratoria de siete años prevista en el art. I24 ER, como así han hecho por ejemplo Francia y Colombia.

En segundo lugar, la creación de la Corte no obsta para que las jurisdicciones nacionales continúen siendo la principal, sino la única, instancia para la sanción de aquellos crímenes de guerra que no sean cometidos ni a gran escala ni de manera sistemática en ejecución de un plan o política ${ }^{27}$. Esta es en nuestra opinión la consecuencia de la aplicación de los arts. 8(I) y I7(I) (d) ER que recogen los elementos relativos al umbral de gravedad necesario para que la Corte pueda ejercitar su jurisdicción material sobre los crímenes de

${ }^{22}$ Como Pignatelli y MeCA, F., La Sanción de los Crímenes de Guerra en el Derecho Español: Consideraciones sobre el Capítulo III del Título XXIV del Libro II del Código Penal, Ministerio de Defensa, 2003, p. 9I, ha señalado en relación con el derecho español: «Aún cuando las obligaciones de comportamiento en los tratados en que se contiene el Derecho internacional humanitario son autoejecutivas, no ocurre lo propio con otras, generalmente de resultado, como las que imponen a las Partes en aquellos instrumentos el deber, que estas asumen, de adoptar medidas para la difusión de la normativa humanitaria o para prevenir en su legislación penal la conminación, con sanciones adecuadas de aquella índole, de las infracciones graves de tal normativa. En consecuencia, respecto a las cláusulas de aquellos tratados que no puedan estimarse autoejecutivas, como claramente lo es la ateniente a la obligatoriedad de sancionar penalmente los crímenes de guerra, su aplicación o puesta en práctica en el Derecho interno español requiere de lo que se ha llamado derecho interno internacionalmente indispensable, esto es, de la adopción y publicación de leyes u otras disposiciones de rango inferior que las complementen y desarrollen».

${ }^{23}$ ESCOBAR HeRnÁNDeZ, C., La Progresiva Institucionalización de la Jurisdicción Penal Internacional en GARCÍA ARÁN, M. y LÓPEZ GARRIDO, D. (coord.), Crimen Internacional y Jurisdicción Universal. El Caso Pinochet, Valencia: Tirant lo Blanch, 2000, p. 258.

${ }^{24}$ En el mismo sentido, Pignatelli y MeCA, F., La Sanción de los Crímenes de Guerra en el Derecho Español: Consideraciones sobre el Capítulo III del Título XXIV del Libro II del Código Penal, Ministerio de Defensa, 2003, p. 75 .

${ }^{25}$ Sirva como ejemplo la infracción grave del art. 85(3) PA I de demora injustificada en la repatriación de prisioneros de guerra o civiles.

${ }^{26}$ Arts. II y I2 ER. La Corte sí tendrá jurisdicción, sin embargo, si los Estados no Parte afectados realizan la declaración prevista en el art. I2.3 ER y en la regla 44 RPP.

${ }^{27}$ OlÁsolo Alonso, H., Ataques dirigidos contra personas $y$ bienes civiles $y$ ataques desproporcionados, Valencia: Tirant lo Blanch/Cruz Roja Española, 2007, pp. 305-308. 
guerra previstos en el $\mathrm{ER}^{28}$, y que no deben ser confundidos con el filtro de gravedad al que cada una de las conductas típicas del art. 8 ER ha sido sometida para su inclusión en el ER ${ }^{29}$.

${ }^{28}$ En cuanto a su contenido hay que señalar que mientras el art. 8(I) ER se refiere a que «la Corte
tendrá competencia respecto de los crímenes de guerra en particular cuando se cometan como parte
de un plan o política o como parte de la comisión en gran escala de tales crímenes», el art. I7(I)(d) ER
añade el requisito de la «suficiente gravedad» del crimen de guerra de que se trate para que la Corte
pueda ejercitar su jurisdicción de conformidad con el art. I7(I)(d) ER.
Es necesario recordar que estos dos elementos que conforman el umbral de gravedad de los
crímenes de guerra deben aplicarse primero con respecto a situaciones de crisis en su conjunto -
como por ejemplo el conflicto armado que tuvo lugar en el territorio de la ex Yugoslavia entre I99I y
I995 o la situación de crisis vivida en Rwanda entre abril y junio de I994. Esto se produce en el
marco del proceso de activación previsto en los arts. I3, I4, I5, I8 y 53 (I),(3) y (4) ER, que se configura
como un proceso previo y autónomo con respecto al proceso penal ante la Corte, con un objeto, unas
partes y un procedimiento propios, y dirigido a la determinación de los parámetros personales,
temporales y territoriales que definen las situaciones de crisis con respecto a los cuales la Corte va a
activar su jurisdicción abstracta -o latente- para así poder proceder a la investigación y, en su caso, activar su jurisdicción abstracta -o latente- para así poder proceder a
enjuiciamiento de los delitos presuntamente cometidos en las mismas.

A este respecto hay que subrayar que los parámetros personal, material, territorial y temporal de la jurisdicción de los TPIY y TPIR han sido precisamente definidos por el órgano político que los creó, el Consejo de Seguridad de las Naciones Unidas. En realidad, debido a que han sido creados para conocer de los delitos cometidos en situaciones de crisis particulares, ambos tribunales han sido caracterizados como tribunales ad hoc. Por el contrario, la Corte es definida en los arts. I, 5, II y I2 ER como una institución de carácter permanente que podrá actuar en relación con los delitos de genocidio, de lesa humanidad y de guerra cometidos en situaciones de crisis o conflictos armados que se produzcan tras la entrada en vigor del ER en el territorio de: (i) un Estado Parte; o (ii) cualquier Estado, si los delitos han sido presuntamente cometidos por los nacionales de un Estado Parte, o si la Corte actúa a instancia del Consejo de Seguridad. Como resultado de la diferencias significativas entre la Corte y los tribunales ad hoc en este punto, los arts. I3, I4, I5, I8 y 53(I), (3) y (4) ER han creado un proceso de activación dirigido a la determinación de los ámbitos personal, territorial y temporal que definen las situaciones de crisis o conflictos armados con respecto a las cuales la Corte va, primero, a activar su jurisdicción abstracta -o latente- y a continuación ejercitarla mediante la investigación y enjuiciamiento de los delitos presuntamente cometidos en dicha situación de crisis o conflicto armado. Ver sobre esta cuestión Corte Penal Internacional: ¿Dónde Investigar? Especial Referencia a la Fiscalía en el Proceso de Activación, Valencia: Tirant lo Blanch/Cruz Roja Española, 2003, pp. I05-II7 y 39I-403.

Sólo activada la jurisdicción abstracta o latente de la Corte con respecto a una cierta situación de crisis, se procederá a su investigación de conformidad con los arts. 54 y ss ER. Posteriormente, cuando a raíz de dicha investigación se dicte, según lo previsto en el art. $58 \mathrm{ER}$, una orden de arresto o de comparecencia contra uno o varios individuos por su presunta responsabilidad penal en los incidentes contenidos en tal orden -por ejemplo el bombardeo del casco antiguo de Dubrovnik el 6 de diciembre de I99I- nacerá stricto sensu un proceso penal, cuyo objeto, según la terminología del ER, estará formado por «casos» o «asuntos» en lugar de situaciones de crisis o conflictos armados en su conjunto. Será sólo en el momento de decidir si se inicia o no un caso mediante la emisión de una orden de arresto o de comparecencia a petición de la Fiscalía cuando el umbral de gravedad de los crímenes de guerra habrá de ser aplicado de nuevo en relación con los incidentes específicos a que se refiere la solicitud de la Fiscalía.

Debido a que Corte se configura como una instancia jurisdiccional de ultima ratio cuya actividad se circunscribe a la investigación y enjuiciamiento de los crímenes que menoscaban de manera más grave los valores superiores de la comunidad internacional, y a que aquella parte del umbral de gravedad prevista en el art. I7 (I) (d) ER se aplica no sólo con respecto a los crímenes de guerra sino también con respecto a los crímenes contra la humanidad y al delito de genocidio (y ello con independencia de los elementos contextuales de estas dos últimas categorías de delitos), entendemos que para la activación de la jurisdicción abstracta o latente de la Corte con respecto a un determinado conflicto armado se requiere la existencia de un fundamento razonable para creer que en el mismo se hayan producido de manera sistemática (de acuerdo a un plan o a una política) o generalizada (a gran escala) delitos tipificados en el ER. Una opinión contraria es sostenida por PELLANDINI, C., «Los Crímenes de guerra», en Justicia Penal Internacional: Una Perspectiva Iberoamericana, Casa de América, 2000, p. I23, quien afirma que el umbral de gravedad previsto en el ER no es excluyente y, 
En tercer lugar, la Corte constituye una jurisdicción de ultima ratio que únicamente conocerá de los crímenes de guerra cometidos en un determinado conflicto armado, si conforme al art. I7 ER, las jurisdicciones nacionales afectadas: (i) no llevan a cabo investigación o enjuiciamiento alguno (inacción a priori); (ii) inician sus actuaciones pero las suspenden antes de finalizarlas sin razón técnica que lo justifique a la luz de sus

por tanto, deja a la Corte la posibilidad de investigar crímenes de guerra cometidos de manera aislada.

Una vez que la Fiscalía solicita la emisión de una orden de arresto o de comparecencia, el umbral de gravedad de los crímenes de guerra, en cuanto que condición objetiva de procedibilidad, debe ser aplicado en relación con los incidentes específicos en los que se basa la petición de la Fiscalía. En este contexto, la referencia a «en particular» en el art. 8(I) ER, si bien refuerza el umbral de gravedad previsto en el art. I7(I) (d) ER, no parece exigir stricto sensu que los crímenes de guerra que la Fiscalía imputa a la persona objeto de la orden de arresto o de comparecencia deban ser necesariamente parte de un plan o política o de la comisión a gran escala de crímenes de guerra (COTTIER, M. y FEnRICK, W.J. y Sellers, P.V. y Zimmerman, A., «Article 8. War Crimes», en TriffTerer, O. (Coord.), Commentary on the Rome Statute of the International Criminal Court, Baden-Baden: Ed. Nomos, I999, p. I8I). De esta manera, la prueba de que los incidentes específicos sobre los que se basa la petición de una orden de arresto o de comparecencia forman parte de una dinámica de sistematicidad (de acuerdo a un plan o a una política) o generalidad (a gran escala) en la comisión de crímenes de guerra no constituye conditio sine qua non para que la Corte pueda dictar la orden de arresto o comparecencia solicitada y proceder con el caso $^{28}$. Esta parece ser también la posición adoptada por, Pignatelli y MeCA, F., La Sanción de los Crímenes de Guerra en el Derecho Español: Consideraciones sobre el Capítulo III del Título XXIV del Libro II del Código Penal, Ministerio de Defensa, 2003, pp. 74-75, cuando afirma: «Las alternativas que los principios de que se trata suponen son plenamente compatibles, y aun accesorias o conexas, pues, de un lado, para aquellos crímenes de guerra que no alcancen o reúnan los requisitos o criterios alternativos de la comisión como parte de un plan o política o como parte de la comisión en gran escala de tales crímenes a que se hace referencia en el artículo 8.I del Estatuto de la CPI es obvio que la sanción en sede nacional, para la que resulta determinante el principio de justicia universal, resulta, en principio, y dejando a salvo la excepción dimanante de la gravedad suficiente determinante de una resolución de no inadmisibilidad ex artículo I7.I d) del Estatuto de la CPI, la única posible...».

En definitiva, el umbral de gravedad se configura como una auténtica condición objetiva de procedibilidad, de la que los negociadores por razones utilitarias -en este caso con la intención de delimitar el marco de actuación de la Corte, y con ello quizá de reforzar su eficacia dada la limitación de recursos materiales, a aquellas conductas que más gravemente afectan a los valores sobre los que se asienta la comunidad internacional- hicieron depender el ejercicio de la jurisdicción material de la Corte sobre cualquier conducta, sin que con ello se afecte a su carácter típico, antijurídico y culpable y por lo tanto a la existencia misma del delito.

$\mathrm{Su}$ aplicación provocará que las jurisdicciones nacionales continúen siendo la única instancia para perseguir penalmente aquellos crímenes de guerra que se cometan de manera aislada en el desarrollo de operaciones militares, así como aquellos otros que constituyan casos esporádicos de vejaciones de personas protegidas -y en particular prisioneros de guerra o población civil pertenecientes a las otras partes contendientes. Además, la jurisprudencia de la Corte deberá resolver si otras prácticas de carácter más general superan el umbral de gravedad previsto en el ER. Sirva como ejemplo hipotético la práctica de los bombardeos selectivos por las tropas norteamericanas contra áreas residenciales en las que se presumía se encontraban los principales líderes del régimen iraquí, que es analizada en el informe de Human Rights Watch sobre la guerra de Irak (HUMAN Rights WATCH, Off Target: The Conduct of the War and Civilian Casualties in Iraq, diciembre, disponible en <http://www.hrg.org/>). El informe, citando fuentes del Comando Central norteamericano, revela que durante las tres semanas que duró el conflicto en Iraq, se llevarón a cabo unas cincuenta operaciones de bombardeos selectivos, ninguna de las cuales alcanzó su objetivo, y que provocaron la muerte de, al menos, decenas de civiles (cuarenta y dos civiles fueron abatidos en las cuatro operaciones analizadas en detalle por Human Rights Watch en su informe) Surge, por lo tanto, la cuestión de si las bajas entre la población civil son o no consideradas desproporcionadas en relación con la ventaja militar esperada del desarrollo con éxito de las distintas operaciones, y de si la realización de cincuenta operaciones en el espacio de tres semanas puede ser calificado o no como de política o práctica sistemática.

29 Von Hebel, H. y Robinson, D., «Crimes within the Jurisdiction of the Court», en The International Criminal Court. The Making of the Rome Statute, LEE, R.S. (Coord.), I999, pp. I03-IO4. 
respectivas leyes de enjuiciamiento penal (inacción a posteriori); (iii) no tienen la disposición necesaria para llevar realmente a cabo las investigaciones o enjuiciamientos iniciados (falta de disposición); o (iv) no tienen la infraestructura judicial necesaria para llevar a cabo las actuaciones que han iniciado debido al colapso total o parcial de su administración de justicia o al hecho de que carecen de ella (incapacidad) ${ }^{30}$.

En consecuencia, se puede afirmar que la función principal de la Corte es la de seguimiento del desarrollo de las actuaciones de las jurisdicciones nacionales afectadas, de manera que sólo le corresponderá pasar a un primer plano en la investigación y enjuiciamiento de crímenes de guerra cuando las aquéllas permanezcan inactivas o adolezcan de falta de disposición o de capacidad para llevar a cabo sus actuaciones ${ }^{3 \mathrm{I}}$. La configuración de la Corte como un órgano jurisdiccional de vigilancia y control pretende reforzar los sistemas nacionales de sanción de crímenes de guerra a través del incentivo que supone la amenaza de que su inactividad provocará la actividad de la Corte ${ }^{32}$. Al mismo tiempo, la función de supervisión atribuida a la Corte servirá para legitimar implícitamente las actuaciones nacionales que superen los criterios previstos en el art. I7 ER ${ }^{33}$. Este espaldarazo a las actuaciones nacionales se presenta particularmente relevante a la luz de la importancia que el principio de justicia universal tiene en la investigación y persecución de los crímenes de guerra ${ }^{34}$.

En cuarto y último lugar, el art. 53(I)(c) y 2 (c) ER atribuye a la Fiscalía, bajo el control de la Sala de Cuestiones Preliminares («SCP») previsto en el art. 53(3) ER, una amplia discrecionalidad política no reglada para la activación de la jurisdicción abstracta o latente de la Corte con respecto a una determinada situación de crisis (iniciación de la investigación) como para solicitar a la SCP la iniciación de un caso mediante la emisión de una orden de arresto o de comparecencia ${ }^{35}$. En consecuencia, se precisa que no existan razones sustanciales para creer que, aun teniendo en cuenta la gravedad de la actividad criminal y los intereses de las víctimas, la actuación de la Corte no redundaría en interés de la justicia. Entre estas razones se podría incluir el efecto desestabilizador que la Corte pudiera puntualmente producir en procesos de negociación de paz o de transición

$3^{\circ}$ Olásolo Alonso, H., «The Triggering Procedure of the International Criminal Court, Procedural Treatment of the Principle of Complementarity, and the Role of the Office of the Prosecutor», Internacional Criminal Law Review 2005/I, pp. I2I-I46, p. I32.

${ }^{31}$ OlÁsolo Alonso, H., «Reflexiones sobre el Principio de Complementariedad en el Estatuto de Roma», Revista Española de Derecho Militar 82, julio-diciembre 2003, p. 6I.

${ }^{32}$ OlÁsolo Alonso, H., Corte Penal Internacional: ¿Dónde Investigar? Especial Referencia a la Fiscalía en el Proceso de Activación, Valencia: Tirant lo Blanch/Cruz Roja Española, 2003, p. 232.

33 Como Escobar Hernández C., «La Progresiva Institucionalización de la Jurisdicción Penal Internacional», en GARCÍA ARÁN, M. y LÓPEZ GARRIDO, D. (Coord.), Crimen Internacional $y$ Jurisdicción Universal. El Caso Pinochet, Valencia: Tirant lo Blanch, Valencia, 2000, p. 26I, ha señalado: «En ello radica, sin duda, la gran aportación del Estatuto: garantizar plenamente que el enjuiciamiento de los más graves crímenes de trascendencia internacional puede llevarse a efecto, bien sea por la intervención de los tribunales nacionales que actuaría aplicando reglas del principio de jurisdicción universal, bien sea por la intervención de la Corte cuando la primera fórmula no se posible o adecuada».

${ }^{34}$ Para un detallado análisis de la aplicación del principio de jurisdicción universal en el derecho interno español en relación con los crímenes de guerra, ver PignATELLI y MECA, F., La Sanción de los Crímenes de Guerra en el Derecho Español: Consideraciones sobre el Capítulo III del Título XXIV del Libro II del Código Penal, Ministerio de Defensa, 2003, pp. 76-85.

${ }^{35}$ Sobre el principio de oportunidad política no reglada en el marco del ER, ver OLÁSOLO ALONSO, H., «The Prosecutor of the ICC before the Initiation of the Investigations: A Quasi-judicial or a Political Body», International Criminal Law Review, 2003, pp. Iıо y ss. 
democrática, lo que podría aconsejar retrasar la intervención de la Corte. ${ }^{36}$ En estas situaciones, la imprescriptibilidad de los delitos previstos en el ER, incluidos los crímenes de guerra recogidos en el art. $8 \mathrm{ER}$, haría posible este aplazamiento sin que con ello se estuviese necesariamente favoreciendo la impunidad de sus presuntos autores ${ }^{37}$.

A esto hay que añadir que la Fiscalía ha venido desde un principio afirmado su intención, dadas las limitaciones materiales de la Corte, de utilizar la discrecionalidad que le atribuye el art. 53(2) ER para promover el ejercicio de la acción penal contra los responsables últimos de los delitos previstos en el $\mathrm{ER}^{38}$. Por lo tanto, serán una vez más las jurisdicciones nacionales las que continuarán actuando como instancia única para conocer de aquellos crímenes de guerra que la Corte decline investigar o enjuiciar por razones de oportunidad, incluida la posible responsabilidad penal de los mandos intermedios y de los subordinados de rango más bajo que con frecuencia resultan ser los autores materiales de tales delitos ${ }^{39}$.

\section{Análisis del caso Couso}

\section{IV.I. Jurisdicción, Admisibilidad y Marco Procesal Aplicable}

Antes de proceder al análisis del caso desde una perspectiva sustantiva, conviene subrayar que la Corte no tendría hoy jurisdicción para conocer de los hechos descritos en la querella puesto que, a pesar de producirse con posterioridad a la entrada en vigor del ER el I de julio del 2002, tuvieron lugar en el territorio de un Estado no Parte (Irak) y fueron presuntamente cometidos por nacionales de un Estado no Parte (EE.UU.). De manera que, al no ser Estados Parte del ER ni el Estado territorial ni el Estado de nacionalidad de los presuntos responsables, la Corte sólo podría tener jurisdicción si concurre una de las dos circunstancias siguientes:

${ }^{36}$ En esta misma línea parecen definirse los poderes de suspensión temporal de las actuaciones de la Corte atribuidos al Consejo de Seguridad en virtud del art. I6 ER. Por ello, parece que su ejercicio debe limitarse a evitar que la actuación de la Corte en un momento dado pueda restar eficacia a las medidas adoptadas por el Consejo de Seguridad de conformidad con los poderes que le han sido conferidos por el Capítulo VII de la Carta de las Naciones Unidas para restablecer la paz y seguridad internacionales y para poner fin a los actos de agresión.

${ }^{37}$ Art. 29 ER.

${ }^{38}$ Como la Fiscalía de la Corte ha señalado en su llamado Policy Paper: «The global character of the ICC, its statutory provisions and logistical constraints port a preliminary recommendation that, as a general rule, the Office of the Prosecutor focus its investigative and prosecutorial efforts and resources on those who bear the greatest responsi-bility, such as the leaders of the State or organisation allegedly responsible for those crimes» (disponible en <http://www.icccpi.int/otp/otp_policy.html>).

39 Sobre las experiencias prácticas en España y en diversos países de América Latina en la investigación y el enjuiciamiento de crímenes de guerra se pueden consultar entre otros HENCKAERTS, J.M. y DOSWALD-BECK, L. (Coord.), Customary International Humanitarian Law, CICR, Cambridge University Press, 2005; PÉREZ-CEPEDA, A., «La globalización: guerra, prevención y justicia penal internacional», en PÉREZ Álvarez (Coord.), Serta in memoriam Alexandra Baratta, Universidad de Salamanca, 2004, pp. I363 y ss.; AmBOS, K. y MAlarino, E. (Coord.), Persecución Penal Nacional de Crímenes Internacionales en América Latina y España, Fundación Konrad Adenauer/ Instituto Max Planck, 2003 -MAlARINO, E. (Argentina, pp. 7I-74); SANTALLA, E. (Bolivia, p. I05-Io8); STEIner, S. y Moura, M.T. (Brazil, p.I53); GuZMÁn, J.L. (Chile, pp. I89-I94); PonTE, A. (Colombia, pp. 24I-248); HERnÁNDEZ, P. (Costa Rica, p. 295-296); VAQUERANO, N.A. (El Salvador, pp. 326-328); GIL, A. (España, pp. 387-393); NERI, E.P. (México, pp. 435-437); CARO, D.C. (Perú, pp. 483-486); GONZÁLEZ, J.L. (Uruguay, pp. 522-526) y MODOLELL, J.L (Venezuela, pp. 562-565). 
(a) Que el Consejo de Seguridad remita a la Fiscalía de la Corte según lo previsto en el art. I3 (b) ER la situación de crisis generada a raíz del inicio del conflicto armado en Iraq el 20 de marzo de 2003 mediante resolución adoptada conforme al Capítulo VII de la Carta de las Naciones Unidas ${ }^{40}$;

(b) Que el gobierno de los EE.UU. o el gobierno iraquí elegido tras la aprobación de la nueva constitución extienda ad hoc la jurisdicción de la Corte sobre dicha situación de crisis mediante la emisión de una declaración según lo previsto en el art. I2(3) ER y en la regla $44 \mathrm{RPP}^{4 \mathrm{I}}$.

Además, es importante tener en consideración que en ambos casos, el objeto de las actuaciones ante la Corte sería el conjunto de la situación de crisis generada a raíz del inicio del conflicto armado en Iraq el 20 de marzo de 2003 , y no solamente los hechos descritos en la querella de la acusación particular en el Caso Couso.

Únicamente, cuando como resultado de la investigación de dicha situación de crisis, se llegase a la conclusión de que existen «motivos razonables para creer» que el sargento Thomas Gibson, el capitán Philip Wolford y el teniente coronel Philip de Camp son penalmente responsables por las muertes, lesiones y daños ocasionados como consecuencia del ataque al hotel Palestina el 8 de abril de 2003, la Fiscalía de la Corte solicitaría, y la SCP dictaría, una orden de arresto o de comparecencia contra los mismos, iniciándose de este modo un «caso» o proceso penal propiamente dicho ${ }^{42}$.

Y todo ello siempre que se considerase: (a) que los crímenes que se les imputan tienen la suficiente gravedad -valoración que habrá de realizarse a la luz del resto de actividades delictivas que hayan podido cometerse en la situación de crisis objeto de la investigación ${ }^{43}$; y (b) que no existen razones para creer que el enjuiciamiento de estas personas no redundaría en los intereses de la justicia ${ }^{44}$ - principio de oportunidad no reglada en el ejercicio de la acción penal, que según la Fiscalía de la Corte va a ser utilizado para que la acción penal se ejercite únicamente contra los responsables últimos de la criminalidad sistemática o a gran escala que se haya producido en las distintas situaciones de crisis objeto de investigación ${ }^{45}$.

Por otra parte, y aún en la hipótesis remota de que se produjesen las circunstancias arriba mencionadas, la Corte no podría conocer del caso Couso en virtud del principio de complementariedad de la Corte en tanto en cuanto la Audiencia Nacional conozca del mismo ${ }^{46}$. Este es precisamente el sentido de la reciente sentencia del Tribunal Supremo de in de diciembre de 2006 por la que se reconoce la jurisdicción de la Audiencia

${ }^{40}$ Las limitaciones jurisdiccionales del art. I2(2) ER no se aplican a las remisiones realizadas por el Consejo de Seguridad conforme al art. I3(b) ER.

${ }^{4 \mathrm{I}}$ Ver a este respecto, OlÁSOlo Alonso, H. (with STAHn, C. y El ZEIDY, M.M.), «The International Criminal Court's Ad Hoc Jurisdiction Revisited», American Journal of International law, Vol. 99, 2005/3 Issue.

${ }^{42}$ Art. 58(I) y (7) ER.

${ }^{43}$ Art. I7(I)(d) and 8(I) ER.

${ }^{44}$ Art. 53(2)(c) ER.

${ }^{45}$ Como la Fiscalía de la Corte ha señalado en su Policy Paper: «The global character of the ICC, its statutory provisions and logistical constraints port a preliminary recommendation that, as a general rule, the Office of the Prosecutor focus its investigative and prosecutorial efforts and resources on those who bear the greatest responsi-bility, such as the leaders of the State or organisation allegedly responsible for those crimes» (disponible en <http://www.icc-cpi.int/otp/otp_policy.html>).

${ }^{46}$ Ver entre otros los arts. I, I7, y 53(I)(b) y (2)(b) ER. 
Nacional para investigar los hechos que ocasionaron la muerte de José Couso, y que priva de toda eficacia a la decisión de la Sala de lo Penal de la Audiencia Nacional de marzo de 2006 por la que se dejaba sin efecto la orden de búsqueda y captura dictada por el Juzgado Central de Instrucción Núm. I contra los tres principales imputados y se ordenaba el archivo de la querella presentada por la acusación particular.

A este respecto, conviene no olvidar que la Corte no sustituye, sino que complementa, los mecanismos existentes a nivel nacional e internacional para la persecución penal de los delitos recogidos en el ER (incluidos los crímenes de guerra). Y que por lo tanto, la Corte sólo puede ejercer su jurisdicción en casos de (i) inacción a priori o a posteriori de las jurisdicciones nacionales; (ii) de falta de disposición para llevar a buen término sus actuaciones dado que las mismas están dirigidas a proteger a los presuntos responsables o adolecen de un retraso injustificado o de una falta de independencia o imparcialidad que no es compatible con la intención de traer a los mismos ante la justicia; y (iii) de falta de capacidad para tramitar sus actuaciones debido al colapso total o sustancial o la inexistencia de la administración de justicia.

Pero, ¿qué ocurriría en el caso de que pasaran meses o incluso años sin que las solicitudes de asistencia judicial enviadas por el Juzgado Central de Instrucción Núm. I a los EEUU fuesen atendidas ${ }^{47} \mathrm{y}$, lo que es más importante, sin que la orden internacional de detención contra los tres principales imputados fuese ejecutada, impidiendo con ello la apertura del juicio oral?

No creemos que este escenario pueda calificarse, según lo dispuesto en el art. I7(3) ER, como un supuesto de incapacidad de la jurisdicción española puesto que el mismo tendría lugar ante un más que improbable colapso total o parcial -o desmantelamiento- de la administración de justicia en España. Por lo tanto, la Corte sólo podría actuar si el escenario arriba descrito pudiese ser calificado como un supuesto de inacción a posteriori o sobrevenida de la jurisdicción española (aunque sea por causas ajenas a su voluntad) ${ }^{4^{8}} \mathrm{o}$ como un supuesto de falta de disposición derivado de «una demora injustificada en el juicio que, dadas las circunstancias, sea incompatible con la intención de hacer comparecer a la persona de que se trate ante la justicia» ${ }^{49}$.

En todo caso, sirva lo hasta aquí apuntado para subrayar que la probabilidad de que el caso contra el sargento Thomas Gibson, el capitán Philip Wolford y el teniente Coronel Philip de Camp por el ataque contra el hotel Palestina que terminó con la vida de José Couso Permuy el 8 de abril de 2003 termine en la Corte es prácticamente nula, de manera que el análisis que a continuación realizamos de los aspectos sustantivos del caso no pasan de tener un carácter puramente hipotético.

\section{IV.2. El Umbral de Gravedad como Condición Objetiva de Procedibilidad}

Como dijimos en su momento, el art. 8(I) ER no exige como un elemento del tipo objetivo que el ataque contra el hotel Palestina se haya producido «como parte de un plan o política o como parte de la comisión en gran escala de tales crímenes», si bien el umbral de gravedad resultante de la combinación de esta disposición con el art. I7(I)(d) ER constituye una condición objetiva de procedibilidad.

${ }^{47}$ Referidas en el auto de I9 de octubre de 2005 del Juzgado Central de Instrucción Núm. I.

${ }^{8}$ Art. I7(I)(a) ER. Sobre el concepto de inacción a posteriori ver, OlÁSOlo AlOnSO, H. The Triggering Procedure of the International Criminal Court, Martinus Nijhoff, 2005, pp. I47 y ss.

${ }^{49}$ Art. I7(2)(b) ER. 
En este sentido, de los hechos referidos en la sentencia del Tribunal Supremo de II de diciembre de 2006, en el auto del Juzgado Central de Instrucción Núm. I de ig de octubre de 2005 , en la querella de la acusación particular y en el informe del Comité de Protección de Periodistas $(« C P P »)$, podría atisbarse una posible relación entre el ataque al hotel Palestina y el ataque a las sedes de la cadena Al-Yazira y de la televisión Abu Dhabi en Bagdad que tuvieron lugar unas horas antes. Sin embargo, no parece que se pueda deducir de esta posible relación la existencia de un plan o de una política para la comisión de tales delitos, ni mucho menos su comisión a gran escala, siendo en este sentido ostensibles las diferencias con otro tipo de prácticas como las presuntamente acaecidas en los meses sucesivos a la toma de Bagdad en la prisión de Abu Graib.

En todo caso, esto no significa necesariamente que el ataque al hotel Palestina no pueda de ninguna manera alcanzar el nivel de gravedad necesario para que pudiera ser hipotéticamente perseguible por la Corte, puesto que los ataques contra los corresponsales de guerra tienen un efecto particularmente negativo en las personas protegidas por el derecho internacional humanitario. Esto es debido a que, posiblemente, la garantía más importante contra las infracciones graves del derecho internacional humanitario es la presencia de corresponsales de guerra en las zonas de conflicto que puedan informar sobre las infracciones graves cometidas por las partes contendientes -en este sentido cumplen una función particularmente relevante quienes en lugar de limitarse a acompañar a las fuerzas armadas de una de las partes contendientes realizan lo que el art. 79 PA I denomina «misiones profesionales peligrosas en la zona de conflicto armado». A lo que hay que añadir la alarma social despertada en España por el ataque al hotel Palestina como se refleja en el extenso tratamiento que los medios de comunicación nacionales han dedicado a este caso.

\section{IV.3. Elementos contextuales}

Con respecto a los elementos contextuales del delito imputado, conviene señalar que el ataque al hotel Palestina se produjo en el marco del conflicto armado que desde el 20 de marzo de 2003 enfrentaba a las fuerzas anglo-americanas y a las fuerzas armadas iraquíes, de manera que la participación directa de varios Estados en el conflicto elimina cualquier duda sobre su calificación jurídica como conflicto armado de carácter internacional. Además, el ataque al hotel Palestina se encuentra íntimamente relacionado con dicho conflicto armado porque se produjo durante el desarrollo de la operación de toma de Bagdad por la tercera división de infantería del ejército norteamericano y, según fuertes del mismo, pretendía neutralizar un observador, un francotirador o una base lanzagranadas que operaba desde el hotel ${ }^{5 \circ}$.

El carácter protegido o no de las personas y bienes objeto del ataque es una de las cuestiones más controvertidas del caso y sobre la que volveremos más adelante. En cualquier caso, valga por el momento con señalar que si, como alega la acusación particular y numerosos testigos presentes en el hotel en el momento del ataque, el hotel Palestina no estaba siendo utilizado por las fuerzas armadas iraquíes (o por las milicias vinculadas a las mismas) con fines militares -ya sea como puesto avanzado de observación, ya sea como «nido» de francotiradores, ya sea como base operativa para el lanzamiento de granadas- y se encontraba, principalmente, ocupado por miembros de la prensa internacional que no participaban activamente en las hostilidades, deberá ser jurídicamente calificado como un bien de carácter civil protegido por los arts. 52, 57 y 58 PA I.

${ }^{50}$ Ver Informe del Comité para la Protección de Periodistas (CPP), disponible en: <http://www.cpj.org/Briefings/2003/palestine_hotel/palestine_hotel.html>. 
Del mismo modo, los periodistas alojados en el hotel Palestina que, según las informaciones disponibles, se encontraban allí en lo que se conoce como misión profesional peligrosa en zona de conflicto armado y no participaban directamente en las hostilidades, tendrían conforme al art. 79 PA I el estatuto jurídico de personas civiles y, por lo tanto, se encontrarían protegidos por los arts. 49, 50, 5I, 57 y 58 PA I.

Ahora bien, es importante subrayar que en el momento en el que se produjo el ataque al hotel Palestina, el ejército norteamericano sólo controlaba la parte occidental de Bagdad, mientras que el hotel Palestina se encontraba situado en la parte oriental de la ciudad que todavía no había caído bajo el control norteamericano.

En consecuencia, ni el edificio del hotel ni los periodistas que habitaban en su interior se encontraban protegidos por los Convenios de Ginebra puesto que estos últimos se circunscriben (salvo contadas excepciones como es el caso, por ejemplo, de las instalaciones sanitarias) a regular el comportamiento de las partes contendientes con respecto a las personas y bienes que no pertenecen a las mismas y que se encuentran en su poder $^{\text {5I }}$-ya se trate de heridos, enfermos, náufragos, prisioneros de guerra (incluyendo a aquellos periodistas que acompañan a las fuerzas armadas de una de las partes contendientes y que caen en poder del enemigo) o civiles.

El carácter protegido del hotel Palestina y de las personas que se encontraban en su interior se derivaría por tanto del PA I que, no lo olvidemos, no ha sido ratificado por los EE.UU. Ahora bien, el hecho de que los EEUU no hayan ratificado el PA I no les exime de su cumplimiento, al menos en lo que se refiere a la prohibición de dirigir ataques contra personas o bienes de carácter civil, porque, en cuanto piedra angular del principio de distinción en la conducción de las hostilidades y pilar básico del derecho internacional humanitario, forma parte de la costumbre internacional como así lo ha declarado la Sala de Apelaciones de los tribunales ad hoc en su Decisión sobre jurisdicción en el caso Tadic ${ }^{52}$ y más recientemente en su Decisión interlocutoria en el caso Strugar ${ }^{53}$.

Además, en esta última decisión, la Sala de Apelaciones reconoce expresamente que las violaciones graves de dicha prohibición dan lugar a responsabilidad penal individual conforme a la costumbre internacional ${ }^{54}$. De hecho, fue precisamente el carácter consuetudinario de la responsabilidad penal derivada de los ataques dirigidos contra personas o bienes civiles el que en última instancia justificó su inclusión entre los crímenes de guerra previstos en el ER ${ }^{55}$, de manera que ningún Estado puede oponer la no ratificación de la normal convencional (en este caso el PA I) cuya infracción grave (en este caso el lanzamiento de un ataque dirigido contra personas o bienes civiles) se recoge en el ER.

La técnica utilizada por los negociadores de tipificar en el ER los crímenes de guerra de acuerdo con la naturaleza internacional o no internacional del conflicto armado en el marco del cuál se producen, así como la distinción entre los tipos penales derivados de las infracciones graves de los Convenios de Ginebra (art. 8(2)(a) ER) y los tipos penales que tienen su originen en otras violaciones graves de las leyes y usos aplicables en los conflictos

\footnotetext{
${ }^{51}$ Salvo que pertenezcan a Estados neutrales o co-beligerantes con representación diplomática en Estado de que se trate.

${ }^{52}$ Decisión sobre jurisdicción en el caso Tadic, supra nota I6, párrafos III, I26, I27, I34 y I43.

${ }^{53}$ Decisión Interlocutoria en el caso Strugar, supra nota I6, párrafos 9, Io y I3.

${ }^{54}$ Idem.

${ }^{55}$ Ver a este respecto, Von Hebel, H. y Robinson, D., «Crimes within the Jurisdiction of the Court», en LEE, R.S. (Coord.), The International Criminal Court. The Making of the Rome Statute, Kluwer Law International, I999, pp. I03-I04.
} 
armados internacionales (art. 8(2)(b) ER), presenta importantes problemas en el caso que nos atañe.

Así, a pesar de que los delitos de atacar a personas o bienes civiles -tipificados ambos en el art. 8 (2)(b) ER como otras violaciones graves de las leyes y usos aplicables a los conflictos armados internacionales, en este caso del PA I- se configuran en el ER como delitos de mera actividad que se consuman con independencia de que el recurso a la violencia se concrete en un resultado de muerte, lesiones o daños ${ }^{56}$, no existe tipo penal alguno a través del cual se pueda imputar el resultado de muerte de José Couso Permuy. Esta es la consecuencia de que el delito de «homicidio intencional» se encuentra únicamente tipificado como una infracción grave de los Convenios de Ginebra ${ }^{57}$, y en el momento de producirse el ataque al hotel Palestina José Couso Permuy no tenía la condición de persona protegida conforme a dichos Convenios puesto que dicho hotel no se encontraba bajo el control de las fuerzas norteamericanas ${ }^{58}$.

IV.4. Estructura típica de los crímenes de guerra de lanzar ataques contra personas o bienes civiles o de lanzar ataques desproporcionados en el Estatuto de Roma

En su querella, la acusación particular imputa el crimen de guerra de dirigir intencionadamente un ataque contra un bien de carácter civil (en nuestro caso el hotel Palestina), previsto en el art. 8(2)(b)(ii) ER. Sorprende, sin embargo, la no imputación conforme al art. 8(2)(b)(i) ER del crimen de guerra de dirigir intencionadamente un ataque contra personas civiles, particularmente cuando de acuerdo con la posición de la acusación particular los miembros de la prensa internacional que se encontraban alojados en el hotel fueron el objetivo último del ataque. Así mismo, y dadas las declaraciones de las distintas fuentes del ejército norteamericano y de los propios imputados en el sentido de que el hotel Palestina (uno de los edificios más altos de la ciudad) podría haber estado siendo utilizado por las fuerzas iraquíes con fines militares, llama la atención que la querella no impute de manera alternativa, conforme al art. 8(2)(b)(iv) ER, el crimen de guerra de dirigir intencionadamente un ataque contra un objetivo militar cuando se prevea que causará pérdidas civiles incidentales manifiestamente excesivas en relación con la ventaja militar concreta y directa de conjunto que se espera obtener del ataque.

Los ataques dirigidos contra personas o bienes civiles (al igual que ocurre con los ataques desproporcionados) se configuran en el ER -a diferencia de lo que ocurre en la jurisprudencia del TPIY que los ha definido como delitos de resultado ${ }^{59}-$ como delitos de

\footnotetext{
${ }^{56}$ Olásolo Alonso, H., Ataques dirigidos contra personas y bienes civiles $y$ ataques desproporcionados, Valencia: Tirant lo Blanch/Cruz Roja Española, Valencia, 2007, p. II4.

${ }^{57}$ Art. 8(2)(a)(i) ER.

${ }^{58}$ Entendemos que esta es la razón por la cual la querella de la acusación particular no imputa el resultado de muerte de José Couso Permuy como un delito de «homicidio intencional», si bien hay que señalar que existe en la misma una notable confusión entre lo que constituyen infracciones graves de los Convenios de Ginebra y lo que constituyen violaciones graves del PA I. De hecho, en la propia querella se puede advertir un error cuando se refiere al delito de atacar bienes de naturaleza civil como una infracción grave de los Convenios de Ginebra recogida en el art. 8(2)(a)(ii) ER. En realidad, dicho delito constituye una violación grave del art. 52 PA I y aparece tipificado en el art. 8(2)(b)(ii) ER.

59 Sentencia de Apelación de I7 de diciembre de 2004 en el caso Prosecutor $v$. Dario Kordic and Mario Cerkez, Núm. IT-95-I4/2-A, párrafo 67. Ver también las Sentencias de Primera Instancia en los casos Prosecutor v. Blaskic, caso núm. IT-95-I4-T, de 3 de marzo de 2000 (párrafo I80); Prosecutor v. Dario Kordic and Mario Cerkez, caso núm. IT-95-I4/2-T, de 26 de febrero de 200I (párrafo 328); Prosecutor v. Stanislav Galic, caso núm. IT-98-29-T, de 5 de diciembre de 2003 ( párrafos 56 y 62); y Prosecutor v. Pavle Strugar, caso núm. IT-oI-42-T, de 3I de enero de 2005 (párrafo 280).
} 
mera actividad que se consuman con el lanzamiento del ataque, o lo que es lo mismo con la realización de actos de violencia ${ }^{60}$ contra personas o bienes que, además de no tener la naturaleza de objetivo militar, ni pertenecen, ni han caído en el poder de la parte contendiente a la que pertenece quien lanza el ataque (en nuestro caso los EEUU). De ahí, que al no exigirse un resultado lesivo causalmente vinculado al acto de violencia, el elemento subjetivo del tipo tenga una relevancia particular.

Aunque el art. 30 ER establece como elemento subjetivo general para todos los crímenes de guerra el dolo -lo que en principio incluiría también el dolo eventual- la utilización de la expresión «intencionalmente» en la definición de los crímenes de guerra de atacar a personas o bienes de carácter civil introduce un elemento subjetivo específico en los mismos ${ }^{61}$. En consecuencia, se exige que el autor del ataque haya pretendido lanzar el mismo contra personas o bienes que él mismo conocía tenían un carácter civil -o con respecto a los cuales conocía que concurrían aquellas circunstancias de hecho que les atribuían dicho carácter civil. Además, entendemos que cabría incluir también en estos tipos penales los supuestos de ataques indiscriminados, es decir aquellos que el autor no dirige contra un objetivo militar concreto -o conoce que no puede dirigir contra un objetivo militar concreto debido a la falta de precisión o al carácter incontrolado de los efectos del armamento o método de combate utilizado- y donde: (i) el autor es además consciente de que las personas o bienes finalmente alcanzados tendrán necesariamente un carácter civil; o (ii) el autor es al menos consciente de la probabilidad de que las personas o bienes finalmente alcanzados tengan un carácter civil y acepta internamente la producción de este resultado ${ }^{62}$.

Sin embargo, quedarían excluidos aquellos supuestos en los que el autor pretende dirigir su ataque contra lo que considera un objetivo militar, aunque a resultas de dicho ataque el autor sea consciente de que personas o bienes civiles se verán necesariamente afectados o vayan probablemente a verse afectados. En realidad, tanto pronto como se prueba que el autor dirigió el ataque contra lo que pensaba (aunque fuese erróneamente) se trataba de un objetivo militar nos adentramos en el ámbito de la llamada ecuación de proporcionalidad -cuyas infracciones graves dan lugar al delito de ataques desproporcionados previsto en el art. 8 (2) (b) (iv) ER- y salimos del ámbito de aplicación de los tipos penales de ataques intencionados contra personas o bienes civiles.

Ahora bien, ¿qué ocurre si el autor se encuentra en la creencia errónea de que está atacando un objetivo militar, cuando en realidad se trata de una persona o bien de carácter civil, como resultado de no haber adoptado las medidas de precaución exigidas por el art. 57(2) PA I, y en particular la relativa a «hacer todo lo que sea factible para verificar que los objetivos que se proyecta atacar no son personas civiles ni bienes de carácter civil, ni gozan de protección especial, sino que se trata de objetivos militares en el sentido del párrafo 2 del artículo 52 y que las disposiciones del presente Protocolo no prohíben atacarlos»?

En nuestra opinión, en estos supuestos no habrá más remedio que aplicar la normativa sobre el error de tipo prevista en el art. 32 ER, a no ser que el incumplimiento sea tan flagrante -por ejemplo el autor tenía la sospecha de que el objeto del ataque podría no constituir un objetivo militar y decidió no adoptar ninguna medida de precaución a los efectos de evitar la confirmación de sus sospechas y de verse con ello obligado a suspender

\footnotetext{
${ }^{60}$ Mientras el ER no recoge definición alguna de la noción de «ataque», el art. 49(I) PA I recoge la siguiente definición: «Se entiende por 'ataques' los actos de violencia contra el adversario, sean ofensivos o defensivos».

${ }^{6 r}$ OlÁSOlo Alonso, H., Ataques dirigidos contra personas $y$ bienes civiles $y$ ataques desproporcionados, Valencia: Tirant lo Blanch/Cruz Roja Española, 2007, pp. 264-266.

${ }^{62}$ Idem.
} 
el ataque- que pueda afirmarse que en realidad se trató más bien de un ataque indiscriminado ${ }^{63}$.

Así, según el art. 32 ER, cualquier error -ya sea vencible o invencible- sobre las circunstancias fácticas que atribuyen a la persona o bien objeto del ataque la condición de civil excluye el dolo del autor y por lo tanto, al no caber la comisión imprudente de los delitos de atacar intencionadamente a personas o bienes civiles, tendrá que declararse la ausencia de responsabilidad penal del autor.

Por otra parte, la definición del crimen de lanzar un ataque desproporcionado recogida en el art. 8(2)(b)(iv) ER incluye también un tipo subjetivo específico que se aparta del general contenido en el art. 30 ER a raíz del uso de las expresiones «intencionalmente» (referida al hecho de lanzar el ataque) y «a sabiendas» (referida a las pérdidas civiles incidentales manifiestamente excesivas que se esperan del ataque), y que está formado por los elementos siguientes. En primer lugar, habrá que tener en cuenta la representación que el autor se hizo en el momento de decidir el ataque contra un determinado objetivo militar de los daños civiles colaterales («pérdidas incidentales de vidas, lesiones a civiles o daños a bienes de carácter civil o daños extensos, duraderos y graves al medio ambiente natural») que su ataque necesariamente, o al menos probablemente, generaría ${ }^{64}$, con independencia de que los haya sobreestimado o subestimado por error. En segundo lugar, habrá que analizar la representación que el autor se hizo en el momento de lanzar el ataque de la ventaja militar concreta y directa de conjunto que el ataque probablemente le proporcionaría (ventaja militar esperada) ${ }^{65}$, con independencia de que el autor la haya sobreestimado o subestimado por error ${ }^{66}$.

Finalmente, se exige que el autor, tras la aplicación por sí mismo de la regla de proporcionalidad, haya decidido lanzar el ataque contra el objetivo militar de que se trate: (i) con la pretensión específica de causar daños civiles colaterales manifiestamente excesivos (dolo directo de primer grado), (ii) a sabiendas de que el ataque produciría necesariamente daños civiles colaterales manifiestamente excesivos (dolo directo de segundo grado); o al menos (iii) con conocimiento de la probabilidad de que el ataque podría producir daños civiles colaterales manifiestamente excesivos y aceptación interna de que tal eventualidad se realice. $^{67}$

En el supuesto de que se llegue a la conclusión de que el sargento Gibson, el capitán Wolford y el teniente coronel Philip de Camp no actuaron con el estado mental necesario como para ser penalmente responsables por alguno de los tres delitos analizados (ataques contra personas civiles, ataques contra bienes civiles y ataques desproporcionados) habría que declarar su falta de responsabilidad penal, conforme al ER, por la muerte de José Couso Permuy. Esta sería la consecuencia de varios factores que concurren en el caso objeto de estudio a pesar de que por regla general el hecho de que el lanzamiento de un ataque no de por sí mismo lugar a responsabilidad penal conforme al ER -recordemos que el ER sólo

${ }^{63} \mathrm{Ibid}$, p. 268 .

${ }^{64}$ PFIRTER, D., «Excessive Incidental Death, Injury or Damage», en LEE, R.S. (Coord.), The International Criminal Court: Elements of Crimes and Rules of Procedure and Evidence, 200I, pp. I49I5O.

${ }^{65}$ Cono la nota 36 de los EC recoge expresamente «la expresión 'expresión ventaja militar concreta y directa de conjunto' se refiere a una ventaja militar que fuera previsible por el autor en el momento correspondiente». Ver a este respecto, PFIRTER, D., «Excessive Incidental Death, Injury or Damage», en LEE, R.S. (Coord.), The International Criminal Court: Elements of Crimes and Rules of Procedure and Evidence, 200I, p. I5O.

${ }^{66}$ OlÁsolo AlONSO, H., Ataques dirigidos contra personas $y$ bienes civiles $y$ ataques desproporcionados, Valencia: Tirant lo Blanch/Cruz Roja Española, 2007, pp. 276-279.

${ }^{67}$ Ibid, pp. 280-282. 
tipifica aquellas infracciones dolosas graves de la normativa que regula la manera en la que han de conducirse los ataques en situación de combate- no significa que el resultado de dicho ataque no pueda ser punible, siempre y cuando el ataque haya sido ilícito desde la perspectiva del derecho internacional humanitario ${ }^{68}$.

En primer lugar, el ER tipifica el delito de «homicidio intencionado» como una infracción grave de los Convenios de Ginebra, conforme a lo cuales, como ya hemos explicado, José Couso Permuy no podría ser considerado como una persona protegida. En segundo lugar, José Couso Permuy tampoco entraría en alguna de las categorías de personas, objetos o áreas especialmente protegidas cuyo ataque, muerte o lesiones dependiendo de los casos- se tipifica en un tipo autónomo dentro del art. 8(2)(b) ER. En tercer lugar, el ataque contra el hotel Palestina tampoco se realizó mediante la utilización de ciertos medios o métodos de combate prohibidos por el derecho internacional humanitario cuyo uso es objeto de un tipo penal autónomo dentro del art. 8(2)(b) ER. En cuarto lugar, al no haberse imputado los daños materiales producidos a raíz del ataque al hotel Palestina no tiene por caso ni tan siquiera analizar si las tres personas imputadas podrían haber incurrido en un crimen de guerra de destrucción de bienes del enemigo no justificada por necesidad militar conforme al art. 8(2)(b)(xiii) ER. A lo que hay que añadir el hecho de que el ER excluye, excepto con respecto a los superiores jerárquicos, la comisión imprudente de los crímenes de guerra previstos en el $\mathrm{ER}^{69}$.

IV.5 Análisis de los hechos del caso Couso a la luz de la tipificación de los ataques contra personas y bienes civiles y de los ataques desproporcionados en el ER

En relación con los hechos del caso, lo primero que hay que señalar es que las imágenes tomadas desde el propio hotel Palestina y las declaraciones de los testigos, incluidas las de las tres personas imputadas, no parecen dejar duda sobre el hecho de que el día 8 de abril del 2003 sobre las once de la mañana el carro de combate Abrams Mi a cargo del sargento Gibson disparó un proyectil que impactó contra la parte superior (piso quince) del hotel Palestina situado en una zona de Bagdad (área oriental de la ciudad) que en aquel momento no estaba todavía bajo el control de las tropas norteamericanas y en cuyo interior se encontraban personas que no pertenecían a las mismas -con independencia de que miembros de las fuerzas armadas iraquíes operasen o no desde dicho hotel.

Tampoco parecen existir discrepancias sobre el hecho de que el proyectil disparado por el sargento Gibson se dirigiese contra la parte superior del hotel Palestina. En realidad, el carro Abrams Mi giró su torreta en dirección al hotel Palestina diez minutos antes del disparo y ajustó durante dos minutos su cañón de disparo. Por lo tanto, a pesar de que el carro de combate Abrams Mi se encontraba en uno de los extremos del puente AlJumhuriya, el impacto sobre el hotel Palestina no parece que pueda haber sido fruto de un error en las coordenadas de disparo.

Conforme al art. 52 PA I, tan pronto como una instalación civil se utiliza para fines militares pierde su carácter protegido hasta que no cesa su utilización para tales fines. Por lo tanto, si miembros de las fuerzas iraquíes operaban desde el hotel Palestina, aquel área del hotel desde la que estuviesen operando había dejado de encontrarse protegida y podía ser objeto de ataque, y ello con independencia de la presencia en la misma de periodistas internacionales que tenían el estatuto de civiles. Sólo la ecuación de proporcionalidad actuaría como límite al derecho de las tropas norteamericanas a efectuar dicho ataque.

\footnotetext{
${ }^{68}$ Ibid, pp. II5-II6.

${ }^{69}$ La única excepción es el reclutamiento, alistamiento y utilización activa en las hostilidades de niños menores de quince años.
} 
Ahora bien, es importante subrayar que de las declaraciones y materiales analizados surgen importantes interrogantes sobre la presencia de un observador, de un francotirador o de una base iraquí para el lanzamiento de granadas en la parte superior o en la recepción del hotel Palestina.

En primer lugar, las distintas versiones dadas por diversas fuentes del ejército norteamericano sobre la naturaleza exacta del objetivo militar que se dice operaba desde el hotel Palestina levantan sospechas sobre su existencia real y sobre el hecho de que la intención última del disparo fuera su neutralización.

En segundo lugar, sorprenden las contradicciones en las declaraciones realizadas por los tres imputados, y en particular como señala el CPP las contradicciones entre las distintas versiones del evento dadas por el capitán Wolford ${ }^{70}$.

En tercer lugar, las declaraciones de numerosos periodistas presentes en el hotel Palestina en el momento del ataque coinciden en negar la presencia de observador o francotirador alguno, y mucho menos de una base iraquí para el lanzamiento de granadas, en el hotel Palestina en el momento de producirse el impacto ${ }^{71}$.

En cuarto lugar, es también reseñable las enormes discrepancias entre las declaraciones de los periodistas presentes en el hotel Palestina -en el sentido de que el hotel era fácilmente identificable y, lo que es más importante, que las tropas norteamericanas podían identificar fácilmente a los periodistas debido a que se habían pasado la veinticuatro horas anteriores en los balcones de sus habitaciones y en la azotea del hotel filmando las operaciones militares que se habían producido principalmente en la parte oeste de Bagdad- y aquellas otras de los imputados y de ciertas fuentes norteamericanas -en el sentido de que ni la tripulación del carro de combate ni sus superiores jerárquicos conocían ni donde se ubicaba el hotel Palestina ni que en el mismo se alojaban numerosos periodistas.

Además, llama poderosamente la atención el hecho de que el sargento Gibson y su tripulación fueran capaces de descubrir a un observador con prismáticos (o a un francotirador dependiendo de las versiones) en la azotea del edificio y sin embargo no fueran capaces de observar que en esa misma azotea y en los balcones de las distintas habitaciones del hotel se encontraban decenas de personas filmando y tomando fotografías ${ }^{72}$.

Finalmente, el ataque previo contra las sedes de la cadena Al-Yazira y de la televisión Abu Dhabi ${ }^{73}$ el mismo día 8 de abril de 2003 puede ser indicativo de una intención bien distinta de la manifestada por los imputados al llevar a cabo el ataque contra el hotel Palestina. Ahora bien, la conexión entre ambos ataques no pasa de ser una mera hipótesis de trabajo, sobre todo a la luz de que las sedes de la cadena Al-Yazira y de la televisión Abu Dabhi se encuentran en la parte oeste de Bagdad donde fuertes enfrentamientos se habían producido durante todo el día 7 de abril y la mañana del 8 de $\mathrm{abril}^{74}$.

Ahora bien, a pesar de los interrogantes generados por los factores que acabamos de mencionar, la cuestión clave a resolver, dada la estructura particular de los delitos

\footnotetext{
${ }^{70}$ Auto del Juzgado Central de Instrucción Núm. I de i9 de octubre de 2005.

${ }^{71}$ Idem. Ver también la querella de la acusación particular.

${ }^{72}$ Informe del CPP.

${ }^{73}$ Auto del Juzgado Central de Instrucción Núm. I de i9 de octubre de 2005.

${ }^{74}$ Informe del CPP.
} 
imputados, es la de determinar cuál fue la representación que se hizo el autor (sargento Gibson), así como la persona que dio la orden de efectuar el disparo (ya sea su superior inmediato el capitán Wolford o el teniente coronel Philip de Camps), sobre la naturaleza militar o civil del objetivo contra el que el proyectil fue disparado.

Como ya hemos señalado, resulta irrelevante cual era la naturaleza real de dicho objetivo puesto que en caso de error del autor sobre la misma nos encontraríamos con un error de tipo que, con independencia de su carácter vencible o invencible, no sería punible en un sistema como el del ER en el que no se tipifica la comisión imprudente de lo crímenes de guerra recogidos en el mismo -y menos aún en relación con los delitos de lanzar ataques contra personas o bienes civiles o de carácter desproporcionado que requieren un tipo subjetivo más exigente que el general del art. 30 ER.

Del mismo modo, el hecho de que se hayan podido producir incumplimientos de las medidas de precaución requeridas por el art. 57 PA I -tales como la falta de transmisión por parte del Mando Central en Qatar, o del Mando de la tercera división de infantería en Bagdad, a las tripulaciones de los carros de combate (y a los jefes de compañía que los dirigían) de la información relativa a la concentración de corresponsales de guerra en el hotel Palestina y a las coordenadas de dicho hotel ${ }^{75}$, o la no adopción de las medidas al alcance de la tripulación del carro de combate para verificar que el edificio sobre el que se proyectaba atacar (en este caso el edificio del hotel Palestina) no tenía un carácter civil ${ }^{76}-$ resulta irrelevante puesto que en ningún caso parece que dicho incumplimiento haya podido ser tan flagrante como para que pueda hablarse de un ataque indiscriminado ${ }^{77}$.

En consecuencia, si el sargento Gibson, el capitán Wolford y el teniente coronel Philip de Camps se representaron, como así manifiestan en sus declaraciones ${ }^{78}$, que el proyectil iba dirigido contra un objetivo militar -ya se tratase de un observador, de un francotirador o incluso de una base iraquí para el lanzamiento de granadas instalada en la recepción del hotel ${ }^{79}$ - no quedará más remedio que analizar su posible responsabilidad penal a la luz de la ecuación de proporcionalidad.

Desde esta perspectiva parece poco factible que los imputados se representaran como manifiestamente excesivas las perdidas civiles incidentales que pudieran derivarse de su ataque en relación con la ventaja militar concreta y directa de conjunto esperada de la neutralización del observador, del francotirador o de la base iraquí para el lanzamiento de granadas.

En este sentido, hay que tener en cuenta, por una parte, que a pesar de los numerosos periodistas alojados en el hotel Palestina en el momento del disparo, la munición utilizada parece haber sido destinada a minimizar las posibles pérdidas civiles colaterales que pudieran derivarse del ataque. Así, la tripulación del carro de combate parece haber elegido un tipo de munición (incendiaria) dirigida a reducir los daños que otro tipo de munición (como por ejemplo la munición anti-blindaje) hubiera podido ocasionar al hotel $^{80}$. Como consecuencia, el ataque sólo produjo daños de consideración en las plantas

\footnotetext{
${ }^{75}$ Informe del CPP.

${ }^{76}$ Idem.

${ }^{77}$ No parece que nos encontremos ante un supuesto en el que los autores tenían la sospecha de que el objeto del ataque podría no constituir un objetivo militar y decidieron no adoptar ninguna medida de precaución a los efectos de evitar la confirmación de sus sospechas y de verse con ello obligados a suspender el ataque.

${ }^{78}$ Informe del CPP.

${ }^{79}$ Idem.

${ }^{80}$ Idem.
} 
catorce y quince del hotel Palestina, y, a pesar de los numerosos periodistas alojados en el momento del ataque en el interior del hotel, sólo un reducido número se vio seriamente afectado.

Por otra parte, la ventaja militar que se podía esperar del ataque varía dependiendo de cual fuese exactamente el objetivo militar contra el que se dirigió el mismo. Así, si lo que se pretendía era neutralizar un observador iraquí que desde uno de los edificios más altos de la parte oriental de la ciudad dirigía a través de la radio las coordenadas de fuego de los morteros y lanzagranadas iraquíes ${ }^{81}$, la ventaja militar esperada es sin duda considerable, sobre todo a la vista de los enfrentamientos que se habían producido esa misma mañana y de las dos bajas que el propio regimiento 64 había sustentado en el plazo de una hora ${ }^{82}$.

Lógicamente, la ventaja militar esperada sería inferior si lo que se pretendía neutralizar era un francotirador operando desde la parte superior del hotel Palestina que ya había herido a dos integrantes del regimiento $\sigma_{4}$ esa misma mañana; y todavía sería de menor consideración si de lo que se trataba era de destruir ciertos lanzagranadas situados en la recepción del hotel.

En cualquier caso, fuese cual fuese el objetivo militar que se perseguía, parece difícil afirmar desde una perspectiva estrictamente objetiva la inexistencia que toda duda razonable sobre el hecho de que las pérdidas civiles colaterales finalmente ocasionadas hayan sido «manifiestamente excesivas» a la luz de los objetivos militares que se dice se pretendía neutralizar. De esta manera, ni tan siquiera el resultado del ataque podría ser utilizado como elemento de prueba a los efectos de demostrar que los imputados tuvieron que haberse representado necesariamente el carácter «manifiestamente excesivo» de las pérdidas civiles colaterales que podrían derivarse de su ataque.

Por todo ello, considerando que el elemento clave para la determinación de la existencia o no de responsabilidad penal de los imputados es la aplicación que estos últimos hicieron de la ecuación de proporcionalidad, y dado que el art. 66 ER obliga a absolver a todo acusado a no ser que la Sala de Primera Instancia esté convencida de la culpabilidad del acusado «más allá de toda duda razonable», parece poco factible que los mismos hayan incurrido en responsabilidad penal a la luz del ER.

\section{Conclusión}

Las reflexiones vertidas en las secciones anteriores a la luz del caso Couso han pretendido mostrar los problemas jurisdiccionales y procesales, además de los derivados de la aplicación del principio de complementariedad y del umbral de gravedad, con que a buen seguro se enfrentarán quienes lleven ante la Corte casos aislados por crímenes de guerra. Sin duda, estos problemas debieron haber sido tenidos en cuenta por el legislador español antes de aprobar el más que problemático artículo 7 (2) de la Ley Orgánica I8/2003, de Io de diciembre de 2003 , de Cooperación con la Corte Penal Internacional, que requiere al Ministerio Fiscal y a los órganos jurisdiccionales españoles de abstenerse de conocer y de remitir al denunciante o querellante a la Fiscalía de la Corte cuando los hechos objeto de su

\footnotetext{
${ }^{81}$ Idem.

${ }^{82}$ Idem.
} 
denuncia o querella puedan dar lugar a responsabilidad penal conforme al ER y no hayan sido presuntamente cometidos ni en territorio español ni por nacionales españoles ${ }^{8_{3}}$.

Así mismo, las secciones precedentes muestran como la particular tipificación de los crímenes de guerra en el art. 8 ER (y en particular la relativa a los ataques dirigidos contra personas y bienes civiles y a los ataques desproporcionados), así como el tratamiento que de ciertas figuras de la parte general realiza el ER (como por ejemplo la exclusión de responsabilidad penal por errores de tipo vencibles), llevan a concluir la ausencia de responsabilidad penal a la luz del ER por hechos como los que son objeto del caso Couso. Ahora bien, esto no significa necesariamente que los hechos objeto del caso Couso tampoco den lugar a responsabilidad penal conforme al ordenamiento jurídico español en cuanto que el abanico de conductas estrechamente ligadas a la existencia de un conflicto armado que son tipificadas por este último es, sin duda, más amplio.

\footnotetext{
${ }^{83}$ Ver a este respecto, OlÁsOlo Alonso, H., «Spain», en LATTANZI, F. y KRESS, K. (Eds.), The Rome Statute and Domestic Legal Orders Vol II: International Cooperation and Judicial Assistance, Il Sirente/ Nomos, 2006, pp. 345-380.
} 